\title{
Physician-assisted dying will be guided by Court ruling for now
}

$\mathrm{C}$ anadian doctors are now free of the threat of criminal prosecution if they assist patients in ending their lives, following the federal government's failure to pass legislation governing assisted dying by a June 6 deadline.

The Supreme Court of Canada imposed the deadline after striking down sections of the Criminal Code that pertain to assisted suicide in February 2015. The so-called Carter decision specifies that doctors may assist competent adults who clearly consent to such aid if they have "grievous and irremediable" medical conditions that cause enduring, intolerable suffering. That decision now guides doctors in the absence of a federal law.

On June 3, the House of Commons approved Bill C-14, which has a narrower definition of who qualifies for aid in dying; the Senate is now reviewing the bill. It would permit doctors, nurse practitioners and pharmacists to participate in assisted dying when asked by a competent adult who has a "serious and incurable" illness, disease or disability, for whom death is likely "in the foreseeable future."

Senate leaders have said they will propose amendments, including redefining who can receive aid in dying. Any changes must return to the House of Commons and be voted upon again.

Until the bill is passed, "it will be legal [for doctors] to end a person's life," Health Minister Dr. Jane Philpott said at the National Health Leadership Conference on June 6. "It's a daunting prospect."

Philpott urged the Senate to pass the bill swiftly rather than letting the Supreme Court ruling stand. She praised provincial and territorial regulatory authorities for the guidelines they have already issued for physicians, but said they are insufficient.

"Doctors may have inadequate legal protection, and I expect that in these early days, many physicians will be extremely reluctant to provide

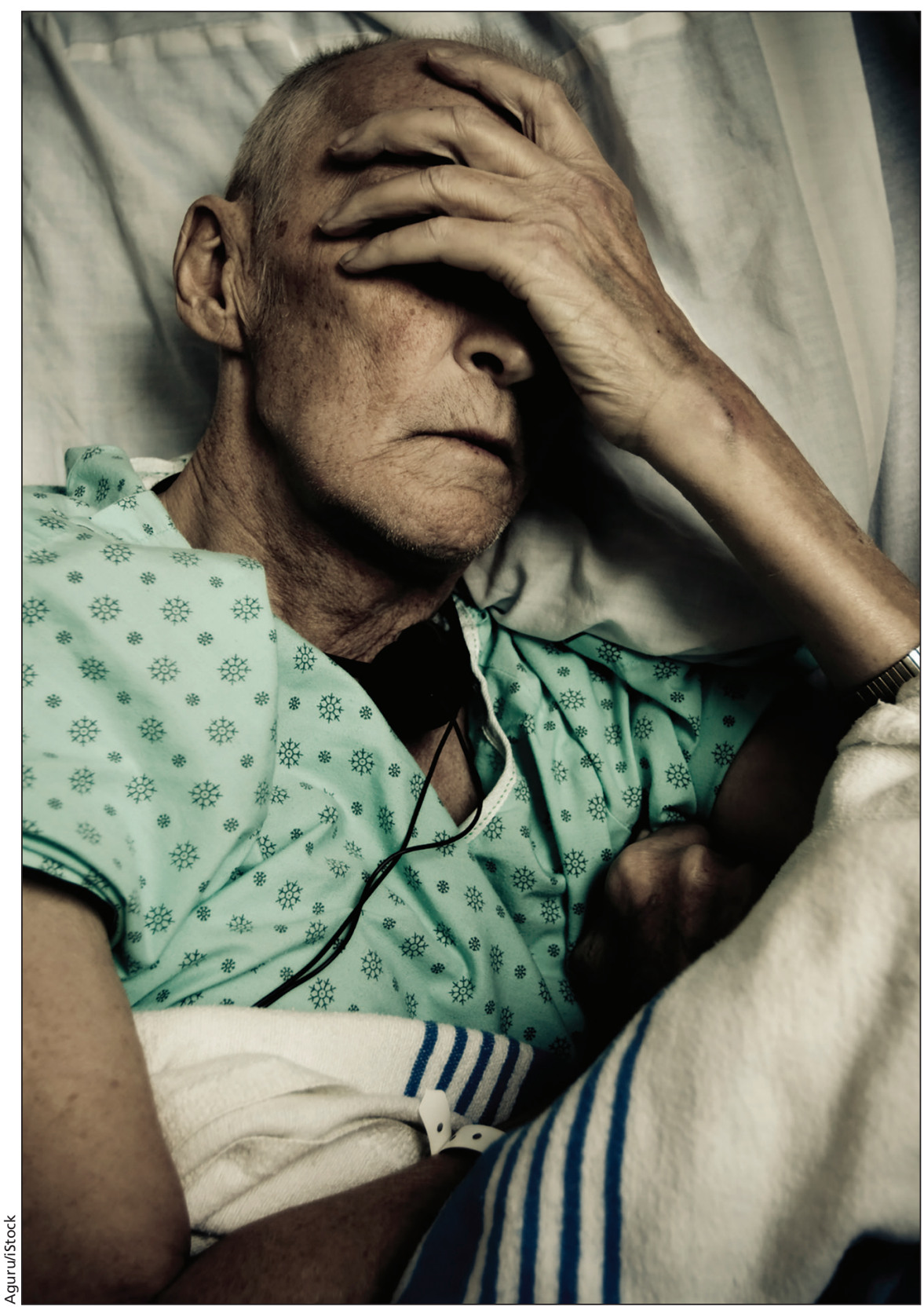

Doctors can provide assisted dying to competent adults who clearly consent to such aid if they have "grievous and irremediable" medical conditions that cause enduring, intolerable suffering.

assistance to patients wanting medical assistance in dying.'

The Canadian Medical Protective Association, which provides liability coverage for more than 92000 Canadian doctors, states that "it expects it will be necessary in many cases to retain legal counsel to assist those of you faced with requests in navigating a patient's eligibility ... to ensure that the necessary safeguards are met, and that the medical assistance is carried out in a way that minimizes your medical-legal risks." 
Without legislation, there is definitely no legal protection for nurses, pharmacists and other health care professionals, because the Supreme Court ruling does not specifically mention them.

The Canadian Nurses Association (CNA) is advising members not to participate. "We will continue to advocate for clients and to provide comfort care for those who are dying and continue creating and implementing a nursing care plan ... around endof-life care," said Chief Executive Officer Anne Sutherland Boal.

Other organizations, including the Canadian Society of Palliative Care Physicians, are urging staff to be cautious and to advise patients to get a court order if they seek a hastened death, said Past President Dr. Susan MacDonald.

But asking patients to get a court order because federal politicians did not act quickly enough to meet the Supreme
Court deadline imposes a substantial barrier, said Dr. James Downar, a critical care and palliative care physician at the University Health Network in Toronto. He urged the federal government to amend the bill to keep it consistent with the intent of the Carter decision, to avoid potential legal challenges.

"It's better to get it right than to get it fast," Downar said.

Some organizations disagree. The Canadian Medical Association (CMA), the College of Family Physicians of Canada, the Royal College of Physicians and Surgeons of Canada, HealthCareCAN, the Canadian Pharmacists Association and the Canadian Nurses Association all support swift passage of C-14. They note the bill includes a commitment that the federal government will continue studying the issue of mature minors and people with mental illness who might seek assisted dying.
Laws in Belgium and the Netherlands were amended after the governments studied the role of advanced directives and other issues, said Dr. Jeff Blackmer, CMA's vice-president, medical professionalism. "We think [Bill C-14] represents a really reasoned, cautionary approach, particularly with the initial legislation," he added.

The Royal College of Physicians and Surgeons of Canada also supports an additional period of reflection to "fine tune" the legislation once passed, said President Dr. Kevin Imrie. While the absence of a law "is not an immediate catastrophe," Imrie predicts an increase in the number of requests for assisted dying. "Our concern is that without a legislative framework, there will be variability across the country." - Laura Eggertson, Ottawa, Ont.

CMAJ 2016. DOI:10.1503/cmaj.109-5290 